\title{
Acute Ingestion of Vitamin C Decreases Blood Pressure and Plasma Viscosity in Young Adult Male and Female Human Subjects.
}

\author{
Blessing Omolaso ${ }^{\mathrm{a}}$, Christopher Akintayo ${ }^{\mathrm{a}}$, Wilson Amuta ${ }^{\mathrm{a}}$, Dr. \\ OlutundeAdegbite ${ }^{\mathrm{a}}$ and DrFrancis Oluwole ${ }^{\mathrm{b}}$ \\ ${ }^{a}$ Department of Physiology, Bingham University, New Karu,Nasarawa State Nigeria \\ ${ }^{B}$ Department of Physiology, University of Ibadan,Ibadan,Nigeria \\ Corresponding Author's name and address: Blessing O. Omolaso \\ Department of Physiology, Bingham University, P.M.B 005, NewKaru, Nasarawa State, Nigeria
}

\begin{abstract}
This research study was carried out to determine the effect of acute ingestion of vitamin C on blood pressure and plasma viscosity of healthy male and female subjects.1000mg of vitamin $C$ was administered to forty young healthy adults (twenty males and twenty females) between the ages 20-25yrs in Bingham University, Karu, Nasarawa State. The blood pressures and plasma viscosities were obtained before and one hour after the ingestion of vitamin C.1000mg of Vitamin C decreased the blood pressure significantly in both male and female subjects $(P<0.05)$. The plasma viscosity in male and female subjects were reduced but only significant in female subjects $(P<0.05)$. The decrease in plasma viscosity in young female adult Human subject who ingested $1000 \mathrm{mg}$ of vitamin $C$ explains the decrease in blood pressureobserved in this study.
\end{abstract}

Keywords: Vitamin C, Blood pressure, plasma viscosity, human subjects

\section{Introduction}

Hypertension is a common health problem in developed countries and a major risk factor for cardiovascular diseases (CVD) (Castelli, 1984). Its prevalence is on the increase in developing countries where adoption of western lifestyles and the stress of urbanization are not on the decline

Extensive biological and biochemical data suggest plasma Vitamin $\mathrm{C}$ as a factor that may help in prevention of disorders associated with it such as ischemic heart disease and stroke.(Gladys,2008)

Previous studies have focusedon association of blood pressure, plasma vitamin C level and plasma viscosityin normotensive and hypertensive subjects. Most of these studies reported that Vitamin $\mathrm{C}$ bears an inverse relationship with both blood pressure and whole blood viscosity (Ness et al., 1996, Woodward, et al, 1999)

There is little previous information on the impact of vitamin C supplementation on blood pressure and blood viscosity. Information of this kind can provide strong evidence establishing Vitamin $\mathrm{C}$ as a major factor in prevention and/or maintenance of elevated blood pressure disorders. This work studies the effect of acute ingestion of Vitamin $\mathrm{C}$ on blood pressure and plasma viscosity in both male and female healthy young adult between the ages of 19-25yrs.

\section{Materials And Methods}

This research was carried out in the physiology laboratory at Bingham University, Karu, Nasarawa State.The total number 40 human subjects consisting of 20 males and 20 females were used for this study. Blood pressure measurement was carried on the subjects before and one hour after ingestion of vitamin $\mathrm{C}$. Thereafter, $10 \mathrm{mls}$ of venous blood was collected before and one hour after ingestion of $1000 \mathrm{mg}$ of Vitamin C for estimation of plasma viscosity.

The modified needle and syringe method of Reid and Ugwu (1987) was used for the determination of plasma viscosity. Plasma viscosity was measured using $1.0 \mathrm{ml}$ graduated syringe to which a vertical needle was fitted. The results were expressed as relative plasma viscosity (RPV) which is the ratio of the flow time for $1.0 \mathrm{ml}$ of plasma to the flow time for $1.0 \mathrm{ml}$ of distilled water at $37^{0} \mathrm{c}$. 
III. Results

Table 1: shows Mean difference in Diastolic Blood pressure (mmHg) in Male and Female Human Subjects before and after ingestion of vitamin $\mathrm{C}$.

\begin{tabular}{|l|l|l|l|}
\hline Subject & $\begin{array}{l}\text { Mean DBP before } \\
\text { Vitamin C }\end{array}$ & $\begin{array}{l}\text { Mean DBP after } \\
\text { Vitamin C }\end{array}$ & Mean Difference in DBP \\
\hline Female & $65 \pm 4.71$ & $58.6 \pm 4.65$ & $6.4 \pm 1.57^{*}$ \\
\hline Male & $70.4 \pm 6.28$ & $66 \pm 4.94$ & $4.4 \pm 1.2^{*}$ \\
\hline
\end{tabular}

* Significantly (S) different from pretreatment values with $\mathrm{P}$ - value at $\mathrm{P}<0.05$.

Table 2: shows Mean difference in Systolic Blood pressure (mmHg) in Male and Female Human Subjects before and after ingestion of vitamin $c$.

\begin{tabular}{|l|l|l|l|}
\hline Subject & $\begin{array}{l}\text { Mean SBP before } \\
\text { Vitamin C }\end{array}$ & $\begin{array}{l}\text { Mean SBP after } \\
\text { Vitamin C }\end{array}$ & Mean Difference in SBP \\
\hline Female & $107.5 \pm 6.98$ & $101.45 \pm 5.17$ & $6.05 \pm 1.88^{*}$ \\
\hline Male & $118.7 \pm 1.80$ & $111.7 \pm 8.03$ & $7.00 \pm 2.2^{*}$ \\
\hline
\end{tabular}

* Significantly $(\mathrm{S})$ different from pretreatment values with $\mathrm{P}$ - value at $\mathrm{P}<0.05$

Table 3: shows Mean difference in Mean Arterial Blood pressure in Male and Female Human Subjects before and after ingestion of vitamin c.

\begin{tabular}{|l|l|l|lr|}
\hline Subject & $\begin{array}{l}\text { Mean MABP before } \\
\text { Vitamin C }\end{array}$ & $\begin{array}{l}\text { Mean MABP after } \\
\text { Vitamin C }\end{array}$ & $\begin{array}{l}\text { Mean Difference in } \\
\text { MABP }\end{array}$ \\
\hline Female & $79.06 \pm 3.68$ & $72.70 \pm 3.80$ & $6.36 \pm 1.27^{*}$ & \\
\hline Male & $86.36 \pm 5.50$ & $80.73 \pm 5.33$ & $5.630 .97^{*}$ & \\
\hline
\end{tabular}

* Significantly $(\mathrm{S})$ different from pretreatment values with $\mathrm{P}$ - value at $\mathrm{P}<0.05$

Table 4: shows Mean difference in Plasma viscosity in Male and Female Human Subjects before and after ingestion of vitamin $\mathrm{c}$.

\begin{tabular}{|l|l|l|l|}
\hline Subject & $\begin{array}{l}\text { Mean PV before } \\
\text { Vitamin C }\end{array}$ & $\begin{array}{l}\text { Mean PV after } \\
\text { Vitamin C }\end{array}$ & Mean Difference in PV \\
\hline Female & $2.65 \pm 0.41$ & $2.31 \pm 0.33$ & $0.34 \pm 0.11^{* *}$ \\
\hline Male & $2.09 \pm 0.39$ & $1.95 \pm 1.49$ & $0.14 \pm 0.11^{\mathrm{ns}}$ \\
\hline
\end{tabular}

* Significantly $(\mathrm{S})$ different from pretreatment values with $\mathrm{P}$ - value at $\mathrm{P}<0.05$

\section{Discussion}

The result of this present study shows that acute ingestion of vitamin C (1000mg), which is 10 times greater than the Recommended Dietary Allowance decreases blood pressure significantly in young healthy male and female human subjects. This result is consistent with previous findings which demonstrate that vitamin $\mathrm{C}$ in short term trials decrease systolic and diastolic blood pressure (Stephen et al, 2012). Olli et al (2000) associated this decrease in blood pressure to the antioxidant property of vitamin $\mathrm{C}$ by ameliorating the endothelial dysfunction. Although, their research was done on active smokers, this work was done on non- smokers.

Blood pressure is dependent on cardiac output and total peripheral resistance. One major determinant of total peripheral resistance is blood viscosity. In the present study, the effect of acute ingestion of vitamin c on relative plasma viscosity was determined in young health male and female subjects. The result shows a decrease in the plasma viscosity for both male and female human subjects one hour after ingestion of $1000 \mathrm{mg}$ of vitamin C. The observed decrease was significant only in female human subjects. The result of this present study is in agreement with the previous findings (Woodward et al, 1999) except that their result showed significant decrease in plasma viscosity in both male and female human subjects following ingestion of Vitamin C. This result seems to suggest that women have more rheological benefit of vitamin $C$ than their male counterpart.

This observed decrease in plasma viscosity following ingestion of Vitamin $\mathrm{C}$ has been reported to be due to the anti-inflammatory effect of Vitamin $\mathrm{C}$ associated with lowering endothelial dysfunction. (Goya et al, 2006).

The decrease in plasma viscosity in young female adult Human subject who ingested 1000mg of vitamin $\mathrm{C}$ could explain the decrease in blood pressure by Vitamin $\mathrm{C}$ as observed in this study. Blood viscosity is known as the most important determinant of Total Peripheral Resistance on which Blood pressure is dependent. (Guyton and Halls, 2007) 
The effect of vitamin C on Plasma viscosity in male subjects could not account for the significant drop in blood pressure since the effect was not significant. This could mean that there are many pathways to blood pressure lowering property of vitamin $\mathrm{C}$ other than decreasing plasma viscosity and could be gender specific.

\section{References}

[1] Castelli, W.P. Epidemiology of coronary heart disease: the Framingham Study. American Journal of Medicine, 76 ,1984, (Suppl 2A), 4.

[2] Gladys Block, Christopher D. Jensen, Edward P. Norkus, Mark Hudes and patricia B. Crawford Vitamin C is inversely related to blood pressure and change in blood pressure during the previous year in young black and white women .Nutritional journal 7: 2008 35

[3] Goya S. Wannamethee, Gordon D.O. Lowe, Ann Rumley, K Richard Brockdoffer and Peter H. Whincup. Association of vitamin c status, fruits, vegetable intake and markers of inflammation and homeostasis; The American Journal of Clinical Nutrition.83:2006567-574

[4] Guyton and Hall: cardiac output venous return and their regulation; Textbook of medical physiology,11 ${ }^{\text {th }}$ edition;20:2007232-244

[5] Ness AR, Khaw KT, Bingham S, et al. Vitamin C status and blood pressure. J Hypertens.;14:1996503-8. [8761901]

[6] Olli T. Raitakari, Mark R. Adams, Robyn J. McCredie, Kaye A. Griffiths, DMU, Roland Stocker, David S. Celermajer.Oral vitamin $\mathrm{c}$ and endothelial function in smokers: short term improvement but not sustained beneficial effect; Journalof the American College of Cardiology Vol. 35, 2000No. 6,

[7] Reid, H. I. and Ugwu, A. C, A Simple Technique for Rapid Determination of Plasma Viscosity. Nig. J. Physiol. Sci. Vol. 3. 1987 pp. $45-48$.

[8] Stephen P Juraschek, EliseoGuallar, Lawrence J Appel, and Edgar R Miller IIIEffects of vitamin C supplementation on blood pressure: a meta-analysis of randomized controlled trials American Journal Nutrition vol:95 2012 no:5 1079-10882012

[9] Woodward M ; A Rumley; H Tunstall-Pedoe; G D LoweAssociations of blood rheology and interleukin-6 with cardiovascular risk factors and prevalent cardiovascular disease.British journal of haematology 1999;104(2):246-57 